\title{
MODIFICAÇÕES NO ATENDIMENTO DE ENFERMAGEM HOSPITALAR DECORRENTES DO SISTEMA ÚNICO DE SAÚDE (SUS)*
}

\author{
Marcia Regina Antonietto da Costa Melo** \\ Neide Fávero*** \\ Yolanda Dora Martinez Évora** \\ Janete Rodrigues da Silva Nakao**
}

MELO, M.R.A.C.; FÁVERO, N.; ÉVORA, Y.D.M.; NAKAO, J.R.da S. Modificações no atendimento de enfermagem hospitalar decorrentes do sistema único de saúde (SUS). Rev.latino-am.enfermagem, Ribeirão Preto, v. 6, n. 4, p. 5-14, outubro 1998.

Considerando modificações ocorridas no Sistema de Saúde, este estudo analisou a visão de 31 enfermeiros de instituição hospitalar do interior paulista, inserida ao SUS frente às mudanças ocorridas em suas ações, em 1995. Para análise destes depoimentos, obtidos através de entrevistas, utilizamos proposta de BARDIN (1977). Alguns enfermeiros perceberam suas ações diferentes e outros não mas, quando estas são analisadas em seu conjunto, percebe-se que estão voltadas para a complementariedade do ato médico. A inadequação do gerenciamento da assistência realizada pelo enfermeiro, tem contribuído para a não integralidade desta. Sugere-se o aprimoramento gerencial a fim de redirecionar as ações de enfermagem.

UNITERMOS: enfermagem hospitalar, SUS, modificações decorrentes do SUS

\section{INTRODUÇÃO}

A situação de crise social, política, econômica e moral que abate o Brasil nestas últimas décadas, repercute diretamente sobre o setor saúde, com conseqüências sérias na qualidade da assistência que está sendo prestada à população. Em decorrência desta crise, também a enfermagem, que está presente em todas as instituições de saúde, vem se modificando apresentando desmotivação e insatisfação.

O Sistema Único de Saúde (SUS) vigente é o resultado de uma luta constante que vem se dando nestas últimas décadas, para a reorganização do sistema de saúde. A enfermagem brasileira durante este período tem participado com maior ou menor intensidade, dependendo do momento político e dos elementos que participam das entidades representativas da categoria.

A problemática do Setor Saúde precisa ser compreendida e analisada por estes profissionais. Percebese inquietação com a questão quando se observa os temas dos últimos Congressos, onde a Associação Brasileira de
Enfermagem (ABEn) tem proporcionado reflexões sobre o sistema de saúde e o mercado de trabalho de enfermagem.

Esta preocupação esteve presente desde o início da Reforma Sanitária quando a ABEn (Comissão de Serviços) e o Instituto Nacional de Assistência Médica da Previdência Social (INAMPS - Coordenadoria de Enfermagem) atentos com a atuação deste profissional frente as mudanças ocorridas no sistema de saúde, promoveram uma Oficina de Trabalho denominada "Subsídios para a conceituação da assistência de enfermagem, rumo a reforma sanitária", buscando compreendê-la (XAVIER et al. 1987).

No $43^{\circ}$ Congresso Brasileiro de Enfermagem que teve como tema central a assistência de enfermagem, BARROS (1991) no discurso de abertura analisou que "a assistência de enfermagem sem caráter universal, igualitário e sem garantia de qualidade tem sido produto das políticas de saúde dos últimos anos", reproduzindo o modelo biológico, "onde não existe homem, mas o doente, quando não apenas a

\footnotetext{
* Extraído da Tese de Doutorado - MELO, M.R.A.C. O Sistema Único de Saúde e as ações do enfermeiro na instituição hospitalar. Ribeirão Preto, 1996. 155p. Tese (Doutorado) - Escola de Enfermagem de Ribeirão Preto, Universidade de São Paulo e apresentado no II Congresso Internacional de Enfermagem Médico-Cirúrgica em Coimbra - Portugal

** Enfermeira. Professor Doutor do Departamento de Enfermagem Geral e Especializada da Escola de Enfermagem de Ribeirão Preto da Universidade de São Paulo

*** Enfermeira. Professor Associado do Departamento de Enfermagem Geral e Especializada da Escola de Enfermagem de Ribeirão Preto da Universidade de São Paulo
} 
doença", assistência esta oferecida "quase que exclusivamente a nível hospitalar, de forma tecnologizada e desumanizada" (p.11). Esta fala a nosso ver, tenta chamar a atenção dos enfermeiros para a busca do modelo de assistência proposto pela Reforma Sanitária, ou seja, um modelo que contemple a integralidade e a universalidade das ações de promoção, proteção, recuperação da saúde.

Outros estudos sobre o envolvimento do enfermeiro no sistema de saúde ou nos serviços afins têm sido desenvolvidos, porém voltados para a área de saúde pública.

Para ALMEIDA (1991), na rede básica de saúde, as ações de enfermagem passaram a priorizar a assistência médica individual e são auxiliares da consulta médica. Refere que as enfermeiras "organizam a infraestrutura material, pessoal e funcional para assegurar o pronto atendimento. Coordenam, controlam e supervisionam vários setores, executam atividades assistenciais mais complexas e atuam junto à clientela para acomodá-la e encaixá-la à consulta médica" (p.249). Esta análise remete a algumas reflexões sobre os modelos de atendimento uma vez que é no hospital que se espera encontrar o modelo clínico individual cuja finalidade é de recuperar o indivíduo, determinado principalmente pelo saber clínico. E na rede básica, a expectativa é que o atendimento se dê com base no coletivo fundamentado nas ações preventivas e educativas, o que ainda não está ocorrendo.

Entendemos que é um desafio para a enfermagem encontrar um fio condutor para a construção desse modelo assistencial capaz de realizar mudanças e gerar impacto na prática. Isto "pressupõe superar o baixo impacto da assistência na saúde da população, o que se evidencia pela sua descontinuidade e fragmentação, baixa cobertura, iatrogenia, déficit crônico e má distribuição de recursos humanos, alta proporção de pessoal sem qualificação específica, falta de identidade e compreensão do seu objeto de trabalho" (SILVA, 1991, p.5). E para que estas mudanças ocorram é preciso vontade e força política da categoria toda. Isoladamente não se conseguirá mudar, nem mesmo crescer enquanto profissão, por menor que seja este crescimento.

A escassez de bibliografia em relação a enfermagem hospitalar e o seu envolvimento com o modelo de assistência à saúde proposto pelo SUS, levounos a investigar o que tem acarretado o modelo de saúde na instituição hospitalar e como o enfermeiro tem desenvolvido suas atribuições na instituição conveniada com o SUS. Houve mudança em seu cotidiano?

Quando se busca entender a dinâmica da assistência de enfermagem dentro de uma instituição hospitalar, é preciso levar em consideração que em nenhum momento a enfermagem pode ser visualizada como profissão isoladamente. Ela é parte da assistência à saúde prestada dentro da instituição, e constitui-se do trabalho de toda a categoria. Também, é preciso considerar como a assistência de enfermagem está sendo desenvolvida no contexto onde se efetiva o atendimento ao paciente, pois a maioria das ações realizadas estão sob sua responsabilidade. Sabe-se que, na grande maioria dos hospitais brasileiros, este trabalho é centrado no modelo funcional, e que sua prática e organização têm passado por situações polêmicas que tem interferido na quantidade e qualidade deste. A situação tem se agravado ainda mais em conseqüência da crise social e econômica pela qual passa o país, pela indefinição das políticas de saúde e salarial, onde as instituições preocupadas com os gastos, pouco têm se empenhado para a melhoria desse quadro. Também, a constituição da enfermagem em categorias reflete na assistência prestada ao paciente, devido ainda ao grande número de pessoal sem qualificação principalmente no nível hospitalar.

Como previsto pelo SUS, a instituição hospitalar, pública ou privada (conveniada e contratada), faz parte deste como unidade de referência secundária e/ou terciária. Sua inserção requer a redefinição do seu perfil e das suas responsabilidades acarretando mudanças. Está previsto para os hospitais o atendimento dos casos em que a complexidade não permite o seu acompanhamento nas Unidades Básicas de Saúde ou serviços especializados, obedecendo sempre a hierarquização dos serviços de saúde. O paciente deve ser referenciado para a realização de procedimentos diagnósticos ou tratamentos hospitalares e na obtenção do resultado ou da alta hospitalar, ser contra-referenciado à unidade de origem para seguimento.

Pressupõe-se que o paciente ao ser referenciado ao hospital, seja de maior complexidade, cujo problema de saúde não pode ser resolvido na Unidade Básica, necessitando de elucidação diagnóstica ou internação devido ao quadro clínico, cirúrgico ou de urgência, com previsão de internação mais longa, e que necessita de assistência integral. E aqui está contemplada a assistência de enfermagem.

A assistência integral à saúde tem sido um termo bastante citado, principalmente nas instituições hospitalares, quando se discute as possibilidades de se oferecer serviços de qualidade, sem ter, no entanto, um consenso. É preciso entender que esta integralidade não se dá apenas entre os serviços que compõe a rede, mas no tipo de assistência prestada dentro de cada um deles, privilegiando as necessidades da clientela.

Acreditamos que, com todas estas mudanças, o ambiente intra-hospitalar tem sido bastante influenciado pelo sistema de saúde, interferindo no trabalho do enfermeiro. Após a adesão ao SUS pela instituição 
hospitalar, este profissional deve conhecer as mudanças ocorridas, discutir e analisá-las com toda a equipe, de modo a favorecer a assistência eficaz a seus pacientes.

Deste modo, os enfermeiros devem repensar a sua prática, pois o paciente encaminhado ao hospital, necessitará um número suficiente de recursos humanos, materiais e tecnológicos, quer no atendimento na unidade de internação quer no ambulatório hospitalar. Não resta dúvida que o envolvimento do enfermeiro ocorrerá nesta situação, onde a assistência ao paciente deve ser planejada, assim como a orientação e a supervisão por parte deste profissional a toda a categoria de enfermagem.

O presente estudo tem por:

Objetivo Geral - Identificar como as modificações ocorridas no Sistema de Saúde com a implantação do SUS, estão interferindo na assistência de enfermagem na instituição hospitalar.

Objetivo Específico - Identificar como um grupo de enfermeiras da área hospitalar percebem suas ações, após a implantação do SUS na instituição em que atuam.

\section{METODOLOGIA}

Dentro da organização dos serviços de saúde de Ribeirão Preto, o campo de investigação escolhido foi o hospital universitário, nível terciário na hierarquização. $\mathrm{O}$ Hospital das Clínicas (HC) da Faculdade de Medicina de Ribeirão Preto da Universidade de São Paulo teve seu primeiro contrato com o INAMPS em 04/12/1987 e o Termo de Adesão ao Convênio SUDS-SP foi feito nos termos do Decreto Estadual n ${ }^{\circ} 28.410$ de 20 de maio de 1988 (DOE de 21/05/88) e da Resolução CIS/SP nº 49/ 88 (SÃO PAULO, 1988).

Este estudo foi realizado nas unidades de internação clínica, cirúrgica e ambulatorial do HC-Campus e consiste numa pesquisa não experimental ex-pós-fato (depois de ocorrido o fato). Esta indica que ela foi conduzida depois que as alterações da variável independente ocorreram no curso natural dos acontecimentos, tentando compreender as relações entre o fenômeno, como ele ocorre naturalmente, sem qualquer intervenção do pesquisador (POLIT \& HUNGLER, 1991).

A instituição em que o estudo foi realizado está vinculada ao SUS desde 20/05/88 e nossa amostra foi de 31 enfermeiros admitidos entre 1980-1987, de modo a garantir que estivessem adaptados às atribuições a eles inerentes e exercendo normalmente suas funções até o momento da coleta de dados.

$\mathrm{O}$ instrumento de coleta de dados elaborado continha perguntas abertas quanto a sua opinião sobre possíveis transformações ocorridas nos últimos anos, em suas ações, após a inserção do HC ao SUS. Após aquiescência da Comissão de Ética Médica e da Diretora da Divisão de Enfermagem do Hospital das Clínicas da Faculdade de Medicina de Ribeirão Preto - Universidade de São Paulo, foram realizadas as entrevistas com os enfermeiros, no ano de 1995.

A digitação e inserção no software "The Ethnograph", (SEIDEL \& CLARK, 1985) de cada entrevista, favoreceu o agrupamento das categorias segundo o tema das questões da entrevista, subsidiado pela técnica de análise temática para instrumentalizar e operacionalizar a análise de conteúdo referida por BARDIN (1977).

\section{RESULTADOS E DISCUSSÃO}

A enfermagem brasileira atravessa um período de transição com a implantação do Sistema Único de Saúde, que prevê um modelo de assistência integral à saúde. Esta integralidade implica na qualificação da assistência.

JUNQUEIRA (1987) refere que a implantação do sistema requer "novos arranjos organizacionais, que devem dar conta dessa nova realidade e das novas tecnologias necessárias ao desenvolvimento da assistência integral à saúde" (p.53). Dentre estes arranjos, a prática dos serviços de saúde, incluindo o hospital, deve ser redefinida. Entretanto, só ocorrerão mudanças se houver vontade política que oriente e defina a direção deste processo. Neste contexto, cabe à enfermagem, juntamente com os outros setores, participar das discussões e mudanças, buscando a efetivação da assistência integral à saúde.

A assistência de enfermagem tem sido um tema bastante explorado, mas não vem sendo considerada melhor ou pior na maioria dos serviços tendo em vista apresentar indícios de deficiência ou precariedade (BARROS, 1981). Os serviços de enfermagem ainda estão voltados para a doença, orientados para as necessidades individuais, centrado nas tarefas, com objetivos imediatos e executado na sua maioria, por pessoal não qualificado. O HC também apresenta estas características diferindo somente em relação ao pessoal não qualificado que, no momento é minoria, tendo em vista a Lei do Exercício Profissional - Lei $n^{\circ} 7498 / 86$ (BRASIL, 1986).

Nesta instituição, nível terciário na hierarquização do sistema, espera-se que o modelo de assistência esteja voltado para a prestação de ações curativas e preventivas, integrais aos pacientes, que precisam de tecnologia (equipamento e recursos materiais) mais complexa. Nela, procuramos identificar se as ações dos enfermeiros têm 
sido diferentes, tendo em vista o modelo de assistência integral, ações estas que podem estar interferindo na assistência de enfermagem.

É importante lembrar que esta instituição está estruturada no modelo burocrático e o serviço de enfermagem sofre a sua influência. O trabalho da enfermagem é orientado pelo modelo funcional, isto é, dividido em tarefas e procedimentos, cujas funções específicas, de cada categoria profissional, estão descritas em manuais elaborados por comissão ad-hoc, por ocasião da inauguração da instituição em 1979 e revistos em 1984 (SÃO PAULO, 1984). A existência destes manuais, determinando as atribuições de cada um, auxilia os enfermeiros e os demais elementos da equipe na compreensão do que é deles esperado, sendo conflitantes, muitas vezes, com o dia-a-dia.

Dos 31 enfermeiros entrevistados (21 lotados nas unidades de internação e dez na unidade ambulatorial), $14(45,16 \%)$ relataram ter ocorrido e $17(54,84 \%)$ disseram não ter ocorrido mudanças em suas ações após a adesão da instituição ao SUS. Analisaremos estes dados separadamente.

Dentre os $14(45,16 \%)$ enfermeiros que perceberam mudanças, 7 estão lotados nas unidades de internação e 7 na unidade ambulatorial. Observa-se, portanto que, a maioria dos que trabalham na porta de entrada da instituição, ou seja, no local onde são recebidos os pacientes referenciados ou os que procuram diretamente pelo hospital, perceberam mudanças em suas ações mais nitidamente. Quando estimulados a relacionar quais eram, relataram como o trabalho era feito antes e como se desenvolve hoje.

Para os enfermeiros a dinâmica de trabalho era diferente, como mostra as falas a seguir:

"Tinha maior envolvimento com os pacientes, estruturava melhor a assistência, ministrava mais orientação aos profissionais da equipe. Hoje minhas ações se direcionam mais em supervisão e assistência a pacientes graves". " $O$ atendimento era mais completo, porque o tempo disponivel para cada paciente era maior. Hoje o atendimento é mais rápido, portanto a assistência de enfermagem fica prejudicada".

"O enfermeiro no ambulatório tinha maior possibilidade de fazer acompanhamento, orientação. Hoje, tem que fazer avaliação do paciente, das necessidades básicas (parte social e da doença). Tem que trabalhar com outras equipes".

"No ambulatório mudou a avaliação do enfermeiro de modo geral. A triagem é muito rápida pois o número de enfermeiros não é suficiente. $O$ enfermeiro atende as urgências e situações muito específicas. Ficam com a parte administrativa".

Esses relatos levam a crer que o trabalho deles era mais próximo ao paciente, permitindo uma assistência de enfermagem global. Hoje, embora também próxima, a assistência parece ser mais tumultuada, não existindo tempo para um relacionamento efetivo enfermeiropaciente, direcionando-se, mais, ao paciente grave. Quanto ao atendimento ambulatorial parece haver a exigência de maior flexibilidade para a prestação da assistência de enfermagem.

LEOPARDI et al. (1992) citam que, quando os enfermeiros falam sobre o seu trabalho, mostram pelo menos duas tendências: uma onde "o trabalho é centrado no cliente, individualizado e especializado tecnicamente" e outra onde "o trabalho é coletivo, dividido com outras categorias, determinado pela instituição e que faz parte do processo de assistência à saúde". Complementam que os enfermeiros admitem ter o seu trabalho dividido em assistencial e administrativo mas "tendem a supor que somente poderão se sentir gratificados quando estão juntos do paciente, o que denominam de assistência direta" (p.253).

Os dados encontrados neste estudo tendem a corroborar com a centralidade no cliente, no cuidado individualizado, principalmente na fase anterior a adesão da instituição ao SUS. Hoje, o cuidado é ministrado de forma mais rápida, voltado para situações específicas sendo percebido por eles a diminuição da qualidade deste. Quanto à divisão do trabalho, apenas um enfermeiro expressa esta percepção:

"Havia uma divisão de trabalho entre a equipe. Hoje há sobrecarga de trabalho, devido ao aumento do número e complexidade do paciente. Há uma exigência maior. Aumento do número de procedimentos realizados no ambulatório como exames e pequenas cirurgias. Diminuiu o número dos funcionários, devido a isso o enfermeiro faz a função do atendente, do auxiliar e dele próprio".

Talvez essa divisão de trabalho, pouco percebida pelos enfermeiros, fosse devido a possibilidade de cada elemento realizar as atividades determinadas pelo manual da Divisão de Enfermagem, frente ao menor volume de atendimento. Hoje, pela diminuição do quantitativo de funcionários (por vários motivos) e o aumento do número e complexidade do atendimento ao paciente, estas mesmas atividades estão deslocadas, aparentando não haver divisão de tarefas.

Em relação à assistência direta, parece existir, atualmente, uma necessidade maior de sua realização pelos enfermeiros, mas em nenhum momento eles disseram "sentir-se gratificados". Ao contrário, a idéia 
que perpassa é a de que estão realizando estas ações pela falta de outros elementos da equipe:

"O nivel de exigência da instituição com o enfermeiro era menor, porque o paciente era diferente, menos exigente. Hoje, o enfermeiro permanece com cuidados diretos, voltados a pacientes mais complexos".

"Prestava menos cuidado ao paciente. Hoje, no ambulatório, aumentou o número de atendimentos, aumentou o número de procedimentos executados e o enfermeiro faz praticamente tudo: "circula sala", faz curativo".

"Há sobrecarga de trabalho, devido ao aumento do número e complexidade do paciente. Há uma exigência maior. Aumento do número de procedimentos realizados no ambulatório como exames e pequenas cirurgias. Diminuiu o número dos funcionários, devido a isso o enfermeiro faz a função do atendente, do auxiliar e dele próprio".

"Com o aumento do número de pacientes mais complexos e a diminuição do número de funcionários, os enfermeiros passaram a desempenhar funções que eram da competência de outros funcionários, diminuindo assim o seu tempo para executar suas tarefas.

A função do enfermeiro continua definida pelo manual da Divisão de Enfermagem (SÃO PAULO, 1984). Está previsto a ele prestar cuidados a pacientes selecionados por gravidade ou complexidade. Talvez este profissional não executasse anteriormente esse cuidado, tendo em vista o quadro de pessoal ser quantiqualitativamente maior, portanto ele está desempenhando atribuições a ele inerentes.

Embora os enfermeiros tenham relatado estar envolvidos com a assistência direta, percebe-se que eles têm dedicado parte do seu tempo com atividades administrativas, voltadas ao gerenciamento do cuidado de enfermagem. É presente nos discursos a realização delas:

"Maior envolvimento com os pacientes, estruturava melhor a assistência, ministrava mais orientação aos profissionais da equipe. Agora direciona-se mais em supervisão e assistência a pacientes graves".

"Enfermeiro ficava mais na parte administrativa devido maior número de pessoal. A supervisão era mais evidente. Hoje é mais difícil exercer supervisão, devido a sobrecarga de serviço. Isto tem exigido não só do enfermeiro como da equipe toda, deveria haver maior número de funcionário para a assistência ser melhor".

A ação administrativa mais evidenciada foi a supervisão de pessoal, não dando para diferenciar se esta ação está envolvendo atividades educativas ou sendo utilizada para controle de pessoal. As demais, isto é, as referentes ao planejamento, organização, coordenação e avaliação da assistência de enfermagem não foram referidas, embora a instituição as considere como atribuições dos enfermeiros. Entendemos, assim como TREVIZAN (1988), que a ação administrativa é o meio para se atingir o paciente, mas por si só não assegura a prática assistencial, ou seja, é preciso a integração entre ações administrativas e assistenciais.

Também não há consenso, entre os enfermeiros, quanto às ações realizadas. Para alguns, realizavam tanto ações assistênciais como administrativas e continuam realizando, para outros realizavam mais as assistenciais e hoje realizam as administrativas e, ainda outros, o inverso. Porém, um enfermeiro expressou o que fazia e o que faz, manifestando a preocupação com a assistência de enfermagem e a perda do espaço profissional:

"O enfermeiro fazia um trabalho mais assistencial com o paciente. Era possivel acompanha-lo durante o período de internação, assim como a familia. Havia mais interesse do enfermeiro em exercício para melhorar o nivel de assistência de enfermagem. Havia supervisão e gerenciamento adequados. Hoje o enfermeiro é mais um na escala. Não há mais supervisão e perdeu-se o interesse pela melhoria das condições de trabalho. Isto significa que estamos perdendo nosso espaço enquanto profissionais, que apenas exercemos nossa profissão para atender o doente em suas necessidades primordiais (alimentação, medicação, higiene)".

Esta atitude de desinteresse pela melhoria das condições de trabalho referida é preocupante, uma vez que ela é o alicerce para o desenvolvimento da prática de enfermagem. Ainda, quanto ao espaço profissional, acredito que o enfermeiro deve ter competência em sua área de atuação para mantê-lo e mesmo ampliá-lo, caso contrário, quem o fará? Como refere RIBEIRO (1980) "não há vazios que não sejam ocupados e, se os espaços físicos, sociais, culturais ou institucionais que nos cabem, deixarem de ser preocupação nossa, de cada um e de todo o grupo profissional, poderão eles se transformar em problemas maiores para a classe, pois outros tentarão e poderão ocupá-los" (p.21). É preciso estar atento e tomar posição frente a estas situações.

Ainda, relacionado às ações administrativas está o controle. O enfermeiro faz o controle de material e também o preenchimento de guias: 
"Aumentou o número de pacientes, é feito controle de material e o preenchimento de guia para o SUS. Tudo deve ser anotado. Houve uma complexidade maior em relação à burocracia e técnicas que tiveram que ser desenvolvidas".

"O que mudou? Hoje há a apresentação de dados estatísticos para reembolso de verbas, aumentou serviço burocrático".

Os recursos materiais para a área de enfermagem são importantes e interferem diretamente no desenvolvimento da assistência prestada. Como em outras instituições, nas unidades de atendimento do $\mathrm{HC}$ os enfermeiros têm exercido atividades referentes à administração de materiais, não apenas em relação ao seu controle, mas também a previsão, provisão e organização do material permanente e de consumo. Entendemos que esta atividade é importante e que o enfermeiro tem competência para a previsão deles, mas, as demais etapas podem ser delegadas a outro elemento da equipe de enfermagem, com menor qualificação, ou a um técnico administrativo.

Em relação ao preenchimento de guias para prestação de contas, talvez esta atividade, que é essencial para a efetividade da quitação dos gastos da instituição pelo SUS, esteja sendo um desvio de função do enfermeiro, podendo também ser realizada por outro elemento da equipe. Concordamos com OLIVEIRA (1983) de que o papel profissional é caracterizado pelo efetivo exercício da prática. Os comportamentos reproduzidos provocam uma expectativa dos grupos para o desempenho de papéis. Os desvios desses comportamentos compromete a expectativa, acentuando os contrastes entre a formação e a utilização. Acreditamos que o tempo gasto pelo enfermeiro com esta atividade (preenchimento de guias) poderia ser destinado à assistência de enfermagem.

A nosso ver, as ações de natureza administrativa realizadas pelos enfermeiros nesta instituição, têm se dado de modo a "manter" a organização da unidade, o que nem sempre é possível tendo em vista o déficit de materiais e de funcionários existente, consistindo-se basicamente na supervisão e no controle destes.

Outras situações exigem a intermediação deste profissional, mostrando que ele precisa estar alerta para o momento pelo qual a instituição está passando:

"O nivel de exigência da instituição com o enfermeiro era menor, porque o paciente era diferente, menos exigente. Hoje, a comunicação precisa ser melhor com o paciente, familia e com funcionários. Agora pacientes e familiares tem mais conhecimento de seus direitos. $O$ enfermeiro precisa estar atento às necessidades do cliente, tem que ser intermediário muitas vezes entre o paciente e os funcionários pois os pacientes exigem muito. Também, o enfermeiro permanece com cuidados diretos, voltados a pacientes mais complexos".

"Estes pacientes acabam necessitando, além dos cuidados (técnicas) de enfermagem, apoio psicológico e social devido ao tempo no hospital".

O momento atual é propício para o (re)pensar e (re)definir o ato de assistir pelos próprios enfermeiros da instituição, visto as mudanças ocorridas, objetivando oferecer uma resposta mais efetiva às necessidades da profissão e dos pacientes. Além disso, para desenvolver competência profissional, é necessário ampliar os seus conhecimentos. E eles percebem isto:

"O enfermeiro permanece com cuidados diretos, voltados a pacientes mais complexos. $O$ enfermeiro tem que fazer cursos e reciclagem para maior conhecimento da parte teórica". "O enfermeiro tem que se tornar especialista, tem que ter conhecimento mais profundo sobre patologias e os cuidados de enfermagem, tem que ter preparo psicológico para dar assistência a pacientes com câncer. Para o enfermeiro é bom, pois possibilita o conhecimento de mais coisas. O enfermeiro torna-se especializado".

"É preciso se atualizar, mas não temos condições de tempo e equipe adequada. Muitas vezes, o enfermeiro desempenha papéis que na verdade poderia estar delegando e teria condições de assumir o seu verdadeiro papel".

Ainda que timidamente, o enfermeiro esboçou a necessidade das ações pedagógicas, isto é, as ações que envolvem o treinamento, formação e educação continuada para mantê-los habilitados e atualizados, favorecendo a competência profissional. A própria Comissão de Educação Continuada da Divisão de Enfermagem poderia estar intervindo nestes entraves, porém ela encontra-se desativada e não vem exercendo suas atividades há cerca de dois anos. Concordamos com eles de que precisam deter um conhecimento profundo para assumir um trabalho que é dividido por especialidades e por complexidade. É no mínimo intrigante como os enfermeiros percebem esta necessidade e não se unem para, pelo menos, reativar esta Comissão.

Permeando a descrição das ações executadas pelo enfermeiro observa-se que estão voltadas para a atenção individual e curativa, em detrimento das preventivas, mesmo na unidade ambulatorial:

"Tinha maior possibilidade de fazer outras coisas como acompanhamento, orientação dos pacientes, pois havia mais pessoal. Tinha a 
idéia de fazer consulta de enfermagem. Hoje tive que deixar essas coisas especificas da enfermagem, para cobrir outros setores, por falta de outros enfermeiros e funcionários". "Há sobrecarga de trabalho, devido ao aumento do número e complexidade do paciente. Há uma exigência maior. Aumento do número de procedimentos realizados no ambulatório como exames e pequenas cirurgias. Também faz um maior número de técnicas e outras que antes não fazia no ambulatório".

"Acho que aumentou muito o número de pacientes, está se atendendo como nível terciário, pacientes com cuidados e atenção mais complexos. Hoje o atendimento é mais complexo para o nivel ambulatorial. São atendidos pacientes em fase terminal de AIDS, que necessitam de cuidados especiais como sonda vesical de demora, sonda nasoenteral, medicações EV, IM e VO, colheita de sangue. Acho que o ambulatório especializado e o de saúde pública fogem um pouco de suas características quanto a prevenção $e$ orientação".

Com base nos dados obtidos até o momento, observa-se que na unidade ambulatorial é real o aumento da complexidade do atendimento realizado e o enfermeiro tem executado atividades que até então eram inerentes da unidade de internação. Atualmente, são realizados exames e procedimentos mais invasivos, exigindo, desse modo, além das ações preventivas as curativas, cabendo ao enfermeiro harmonizá-las. É por isso que as mudanças nas ações foram sentidas mais nitidamente por estes profissionais. Na unidade de internação, sempre houve atendimento ao paciente mais complexo.

Para categorizar as tarefas, procedimentos e atividades desenvolvidas pelos 14 enfermeiros que fizeram referência a elas, de acordo com a proposta de XAVIER et al. (1987), as ações que predominam são as de assistência, concretamente ofertados à clientela - ações de natureza propedêutica e terapêutica complementares ao ato médico e de outros profissionais e as ações de natureza terapêutica e propedêutica da enfermagem, seguidas das ações de natureza administrativa, principalmente a supervisão de pessoal e o controle. Estes dados são coincidentes aos encontrado por SOUZA \& ADAMI (1991).

Como relatamos no início da discussão, para 17 $(54,84 \%)$ enfermeiros (14 lotados na unidade de internação e 3 na unidade ambulatorial) as suas ações não se modificaram tendo em vista o convênio HC-SUS, entretanto um enfermeiro complementou que:
"O enfermeiro continua fazendo o que fazia antes, só que tem que ter mais atenção pois o paciente é mais complexo e o funcionário deficiente, a supervisão, orientação deve ser realizada com mais rigor".

Esta descrição, tenta mostrar que as ações do enfermeiro não se modificaram e leva-nos a relacionar o controle que este realiza frente aos demais elementos da equipe e que até o momento, em várias falas, foi confundida com a supervisão. Concordamos com FERRAZ (1995) de que os enfermeiros têm-se posicionado como gerentes das unidades de internação, traduzindo-se "numa função de controle realizada mecânica e isoladamente, finalizando-se numa fiscalização dos processos técnicos e das atitudes dos profissionais auxiliares" (p.125).

Ainda para alguns desses enfermeiros, ocorreram as mudanças nas ações, principalmente pela diminuição dos recursos humanos:

"Não pelo SUS mas pela diminuição de funcionários".

"As mudanças que ocorreram não foi devido ao SUS, mas as que surgiram foi devido a questão salarial, que levam as pessoas a não investir como profissional de enfermagem".

Estes entraves interferem no dia-a-dia da enfermagem, pois houve aumento do número de pacientes, conseqüentemente aumento do número de procedimentos e a diminuição de pessoal. Não é possível implementar qualquer ação quando não existe quantitativo de pessoal para executá-lo, não esquecendo que seu aumento é importante mas, por si só, não garante melhoria significativa no trabalho. A nosso ver, o qualitativo pode ser incrementado através de treinamentos e atualização no próprio local de trabalho. Também, não se pode concluir que as mudanças que ocorreram em relação às ações do enfermeiro foram em função do convênio HC-SUS, da evasão dos funcionários da enfermagem, ou pelo desconhecimento e falta de habilidade e atitude compatível do enfermeiro para gerenciar tal situação. DUSSAULT (1992) ressalta que a gestão não é ciência, técnica ou arte mas exige intuição, empatia, visão e imaginação, aspectos estes que parece não estar ocorrendo na enfermagem.

Independente de ter percebido ou não mudanças em suas ações, os dados apresentados levam ao entendimento que o enfermeiro está, cumprindo sua jornada de trabalho, de forma rotinizada, pouco envolvido com o contexto geral. Suas atribuições atuais, quando comparadas com as previstas pelo manual da Divisão de Enfermagem, aparentam estar em rumos distintos, pois os enfermeiros têm executado as atividades que se 
apresentam: um número maior de ações ligadas à assistência direta ao paciente, nem sempre de maior complexidade técnica pela falta de outros profissionais de enfermagem, baseada no "apagar incêndio", ou seja, um trabalho indefinido, sem ter a compreensão deste conjunto, aparentando um descaso para com o cuidado de enfermagem, sem o planejamento e a avaliação deste, reflexo da organização do trabalho centrado no modelo funcional, enfatizando a tarefa e a fragmentação do cuidado ao paciente. É possível ainda dizer, que os enfermeiros perceberam modificações importantes e que elas trouxeram conseqüências mais negativas que positivas para a enfermagem refletindo na assistência prestada. Várias falas já citadas relataram queda da qualidade da assistência de enfermagem. Merece ser mencionado que o enfermeiro percebe a queda da qualidade em relação à assistência prestada mas não percebe e/ou sugere como solucioná-la.

Concordamos com LIMA (1993) de que é preciso uma

"reflexão mais profunda quanto à assistência de enfermagem desenvolvida pelos enfermeiros em suas unidades de trabalho, de forma a poder identificar os conflitos existentes e fazer uma discussão sobre a finalidade do nosso trabalho e definir um projeto de reorientação do trabalho do enfermeiro, resgatando o nosso compromisso com a assistência ao indivíduo, com a população, através da demonstração da nossa competência, desenvolvendo uma assistência de qualidade e integral, neste momento em que se propõe uma reorientação e transformação da assistência à saúde" (p.90).

De acordo com esse raciocínio, faz-se necessário articular e integrar as atividades para a reconstrução deste de enfermagem. O papel do enfermeiro enquanto gerente e agente de mudança reveste-se de importância, uma vez que cabe a ele (re)leitura dos objetivos da organização adequando-os à realidade de saúde na qual ela se insere, ou seja, voltada ao modelo assistencial preconizado pelo SUS.

\section{CONSIDERAÇÕES FINAIS}

Considerando o momento da política nacional de saúde, faz-se essencial ao enfermeiro, percebê-lo e refletilo. O modelo assistencial, contemplando a assistência integral à saúde e a unificação das ações curativas e preventivas, com base na realidade local, exige dos profissionais de saúde o envolvimento e a disponibilidade em querer assumí-lo. Neste contexto, as atribuições da enfermagem devem intencionar atendê-lo, encontrando novas alternativas para uma prática efetiva, comprometida com este momento.

No HC, atualmente, há enfermeiros que perceberam suas ações diferentes e identificaram como a sua causa o convênio HC - SUS e, outros que referiram não ter se modificado. Independente das percepções, hoje, na prática, as ações continuam sendo as mesmas, continuando fragmentadas e mais desqualificadas que anteriormente, voltadas principalmente para a complementariedade do ato médico. A nosso ver os enfermeiros estão, na tentativa de atender a todos, numa ciranda do "apagar fogo", privilegiando a quantidade em detrimento da qualidade, não planejando a assistência a ser prestada. Percebe-se a falta de um fio condutor para o encaminhamento do trabalho, assim como a ausência de um elemento que o coordene, o que pode ser traduzido pela falta de gerenciamento. Frente a isto é possível afirmar que a assistência de enfermagem prestada neste momento, não é a mesma que necessita ser construída alicerçada no modelo de assistência integral.

O que fazer para integrar, nesta instituição, o paciente complexo, o número reduzido de recursos humanos na enfermagem e o redirecionamento das ações do enfermeiro, com o intuito de qualificar a assistência de enfermagem?

Acreditamos que a (re)construção da prática assistencial seja o grande desafio da enfermagem hospitalar. Neste momento, o enfermeiro deve desenvolver sua capacidade de gerenciar pois " $f a z-s e$ necessário que o gerente seja capaz de entender a realidade social interna da organização e tenha conhecimento e habilidade para as práticas administrativas inerentes ao processo de gerenciamento mais adequado às expectativas dos clientes, dos trabalhadores, incluindo aqui os próprios enfermeiros" (FÁVERO, 1996, p.64). Além disso, a utilização de uma metodologia de assistência pode ajudar a redirecionar as ações da enfermagem, redistribuir os recursos humanos proporcionando o atendimento integral ao paciente.

Talvez seja este o espaço que precisa ser (re)conquistado pela enfermagem dentro do HC. Para tanto é preciso ser sujeito desta mudança. Acreditamos que a resolução dos problemas não será apenas às custas do aprimoramento gerencial e técnico e da vontade dos profissionais isoladamente, mas de uma ação conjunta dentro da instituição, das unidades reciprocamente relacionadas e com os mesmos objetivos. 


\section{CHANGES IN CLINICAL NURSING CARE DUE TO THE BRAZILIAN UNIFIED HEALTH SYSTEM(SUS)}

Considering changes in the Health System, this survey analyses the view of 31 nurses from a hospital institution linked to the Brazilian Unified Health System (SUS) in order to learn how they face the changes and their actions in 1995. To better understand the content of the interviews, authors use a thematic analysis proposed by BARDIN (1977). This analysis shows that some nurses recognize a different action after the SUS inclusion and others do not. However, when their actions are analysed as a whole, they are mainly directed to be a physician complementary action. The inadequate management by the nurse has contributed for a not entire nursing care. Authors suggest the management improvement of nurses in order to redirect nursing actions.

KEY WORDS: clinical nursing, SUS, changes in nursing care

\section{CAMBIOS EN ENFERMERÍA HOSPITALARIA DERIVADOS DEL SISTEMA ÚNICO DE SALUD (SUS)}

Considerando cámbios ocurridos en el Sistema de Salud, este estudio analizó la visión de 31 enfermeros de una institución hospitalaria del interior de la provincia de São Paulo insertada en el Sistema Único de Salud (SUS), teniendo encuenta los cámbios ocurridos en sus acciones en 1995. Para el análisis de estas declaraciones, obtenidas a través de entrevistas, utilizamos la propuesta de BARDIN (1977). Algunos enfermeros percibieron sus acciones diferentes y otros no, pero cuando estas acciones son analizadas en su conjunto, verificamos que están dirigidas para complementar el acto médico. La gestión inadecuada de la asistencia realizada por el enfermero está contribuyendo para la no integralidad del cuidado. Los autores sugierem el perfeccionamiento gerencial a fin de redireccionar las acciones de enfermería.

TÉRMINOS CLAVES: enfermería hospitalaria, SUS, cámbios derivados del SUS

\section{REFERÊNCIAS BIBLIOGRÁFICAS}

01. ALMEIDA, M.C.P. O trabalho de enfermagem e sua articulação com o processo de trabalho em saúde coletiva: rede básica de saúde de Ribeirão Preto. Ribeirão Preto, 1991. 297p. Tese (Livre Docência) - Escola de Enfermagem de Ribeirão Preto, Universidade de São Paulo.

02. BARDIN, L. Análise de conteúdo. Lisboa: Persona, 1977.

03. BARROS, M.F.R.J. Uma proposta de padronização de ações de enfermagem na equipe de saúde. Rev. Bras. Enfermagem, v. 34, n. 3/4, p.23242, 1981.

04. BARROS, S.M.P. Discurso de Abertura da Presidente da ABEn - Nacional. In: CONGRESSO BRASILEIRO DE ENFERMAGEM, 43, Curitiba, 1991. Anais. Curitiba, Associação Brasileira de Enfermagem, 1991. p. 11-5.

05. BRASIL. Lei $n^{\circ} 7.498 / 86$ de 25 de junho de 1986. Dispõe sobre a regulamentação do exercício profissional e da outras providências. Diário Oficial da República Federativa do Brasil. Brasília, 26 jun. 1986.

06. DUSSAULT, G. A gestão dos serviços publicos de saúde: características e exigências. Rev. Adm. Públ., Rio de Janeiro, v. 26, n. 2, p. 8-19, 1992.
07. FÁVERO, N. O gerenciamento do enfermeiro na assistência ao paciente hospitalizado. Ribeirão Preto, 1996. 92p. Tese (Livre Docente) - Escola de Enfermagem de Ribeirão Preto, Universidade de São Paulo.

08. FERRAZ, C.A. A transfiguração da administração em enfermagem: da gerência científica à gerência sensível. Ribeirão Preto, 1995. 248 p. Tese (Doutorado) - Escola de Enfermagem de Ribeirão Preto, Universidade de São Paulo.

09. JUNQUEIRA, L.A.P. Organização e prestação pública dos serviços de saúde. Cadernos FUNDAP, v. 7, n. 13, p. 52-6, 1987.

10. LEOPARDI, M.T. et al. O significado da assistência de enfermagem no resultado da assistência à saúde. Rev. Bras. Enfermagem, v. 45, n.4, p. 249-258, 1992.

11. LIMA, M.G. Assistência prestada pelo enfermeiro em unidades de terapia intensiva: aspectos afetivos e relacionais. Ribeirão Preto, 1993. 129p. Dissertação (Mestrado) - Escola de Enfermagem de Ribeirão Preto, Universidade de São Paulo.

12. OLIVEIRA, M.I.R. Enfermagem no contexto da saúde e do desenvolvimento. In: CONGRESSO BRASILEIRO DE ENFERMAGEM, 35, São Paulo, 1983. Anais. São Paulo: Associação Brasileira de Enfermagem, 1983. p. 105-11. 
13. POLIT, D.F.; HUNGLER, B.P. Nursing research principles and methods. 4th. ed. Philadelphia: J. B. Lippincott, 1991.

14. RIBEIRO, C.M. Discurso de posse. In: CONGRESSO BRASILEIRO DE ENFERMAGEM, 32, Brasília, 1980. Anais. Brasília: Associação Brasileira de Enfermagem, 1980. p. 21-3.

15. SÃO PAULO (Estado). Hospital das Clínicas, Divisão de Enfermagem. Manual da Divisão de Enfermagem. Ribeirão Preto: HCFMRP - USP, 1984.

16.

. Decreto $n^{\circ} .28 .410$ de 20 de maio de 1988 e Resolução CIS/SP no 49/88. Institui o Termo de Adesão ao Convênio SUDS/SP - Hospital das Clínicas da Faculdade de Medicina de Ribeirão Preto - Universidade de São Paulo. Diário Oficial do Estado, São Paulo, 21 de maio de 1988.
17. SEIDEL, J.V.; CLARK, J. C. Qualis research. Associates University of Harvard, 1985.

18. SILVA, N.F. /Editorial/ Rev. Bras. Enfermagem, v. 44, n. 4, p. 5, 1991.

19. SOUZA, M.F.; ADAMI, N.P. Assistência: a essência das práticas da enfermagem. In: CONGRESSO BRASILEIRO DE ENFERMAGEM, 43, Curitiba, 1991. Anais. Curitiba: Associação Brasileira de Enfermagem, 1991. p. 42 - 84

20. TREVIZAN, M.A. Enfermagem hospitalar: adminstração e burocracia. Brasilia: Ed. UnB, 1988.

21. XAVIER, I.M. et al. Subsídios para a conceituação da assistência de enfermagem rumo à reforma sanitária. Rev. Bras. Enfermagem, v. 40, n. 2/3, p. 177-180, 1987. 